\title{
Recent updates on massage therapy in oncology
}

\author{
Aura SPINU ${ }^{1}$, loana ANDONE ${ }^{1,2}$, Cristina POPESCU ${ }^{1,2}$, Alexandra SPORICl ${ }^{1}$, Mihaela MANDU $^{1}$, \\ Gelu ONOSE ${ }^{1,2}$ \\ ${ }^{1}$ Emergency Hospital "Bagdasar- Arseni", Bucharest, Romania \\ 2"Carol Davila" University of Medicine and Pharmacy, Bucharest, Romania
}

\section{ABSTRACT}

Background. Many oncologic patients are interesting to find ways to improve their conventional treatment and use massage therapy, alongside other methods of complementary and alternative medicine (CAM), in order to relieve cancer - related symptoms.

Aim. This paper's aim is to evaluate the effects of massage in oncologic patients, adults and children.

Conclusions. Massage therapy appears to be useful in relieving cancer related symptoms. However, more randomized studies are needed to really underline the benefits and the risks of this therapy, so the health professionals should choose the proper method for each patient.
\end{abstract}

Keywords: massage therapy, malignancies, cance

\begin{abstract}
Abbreviations
QoL $=$ quality of life $\quad \mathrm{CAM}=$ complementary and alternative medicine
\end{abstract}

\section{BACKGROUND}

Malignancies are associated with a profound impact on patients' physical and psychological functions and especially in advanced stages, decrease the quality of life (QoL) of affected ones (1). Patients experience symptoms as pain, anxiety, fatique, depression, depending on type of cancer but also on stage of the disease. Breast cancer, one of the most frequent types of cancer nowadays, is a leading cause of death in women worldwide, affecting severely also the QoL by impedimenting the physical aspect of these women $(2,3)$. A complex approach should be implemented as soon as possible in order to optimize the patient's needs and to improve their overall mood (1).

A number of non-medicated therapies such as massage, reflexology, osteopathy, acupuncture, diet, music therapy are known as complementary and alternative medicine (CAM) and have recently been subjected to many studies in order to clarify their efficacy and/or interferences with the conventional treatment in oncologic patients (4). However, further studies are needed to provide solid data in this domain, where dealing with such vulnerable group of patients (5). Both health professionals and patients should be aware of the 
benefits and the risks related to each procedure they want to elect (3).

\section{HISTORICAL DATA. DEFINITION}

Massage therapy is one of the most known therapeutic approaches, dating back in 1600 BC, with many ancient cultures (Chinese, Greek, Indian, Turkish) having their own techniques. Our ancestors found that this method of using touch could relieve pain, produce relaxation and heal injuries and since that time, massage therapy continues to evolve, earning a place as a respectable method of CAM $(6,7)$.

We can define massage as the scientific method of manipulating - with the hands - of the whole human body and consists in 5 basic maneuvers: effleurage, petrissage, friction, pinching and vibration. Oncology massage is the ability to modify the regular massage therapy methods, focuses on patient's needs and it's performed by a therapist who must understand the disease and the consequences of the treatments on human body. The existing literature underlined an amount of benefits in oncologic patients both during and following treatment $(3,8)$. Massage therapy is able to counteract many of cancer symptoms or treatment side effects, being more and more popular among oncologic patients as a supportive care option.

\section{RESULTS OF LITERATURE REVIEW}

There have been many studies of massage therapies in children, but only few were able to prove its efficiency - by now (9). In one study, parents massaged their children diagnosed with leukemia, once a day, 15 minutes before bedtime, for a month, increasing the white blood cells and neutrophils and also, decreasing depression (8).

Another study stated that massage performed on inpatients cancer children, 20 minutes/day for about four days or once a week for four weeks in outpatients, decreased muscular pain, anxiety and discomfort (8).

Regarding chemotherapy-induced nausea and vomiting issues, a randomized controlled clinical trial (70 children and adolescents) showed a significantly less incidence and severity of both symptoms in massage group $(8,10)$.

In a systematic review, on different massage techniques in oncologic children, the authors underlined in conclusions the beneficity of this maneuver in relieving pain - resulted from the cancer itself but also from the treatments side ef- fect - anxiety and nausea $(8,11)$. Sleep disorder is common in pediatric oncology and there is an imperious need to target new treatments to improve this deficiency which often associate with daily time impairments as: anxiety, fatigue, and even psychological consequences $(12,13,14)$. Massage proved its efficacity on sleep patterns in studies, even using activity watches, with inpatients adolescents $(8,13)$.

Massage promoted its positive effects in the treatment of women with breast cancer, reducing stress, depression and anxiety - on one hand and on the other, stimulating the immunity. Researches in the field of molecular - level accomplished in the last decades, clarifying the biological pathways in this domain of complementary therapies, upgraded them as part of methods to improve the QoL of cancer patients. (3).

In a study realized by Kinkead et al. (15), following up to four years 66 breast cancer survivors, whom were performed 45 minutes of massage therapy (Swedish or "light touch"), once a week for six weeks, the fatigue cancer-related was significantly decreased - with more improvements in the Swedish massage group than the "light touch" one.

In 2017, Mao et al. reported in an article about their programme of development, implementation and evaluation of massage therapy for breast cancer patients undergoing chemotherapy in an academic medical center. They offered 1,090 massages - between august 2015 and april 2016 - and 692 (63\%) were accepted with a result of decreasing (self- reported) anxiety, nausea, pain and fatigue without any adverse event noted. In the end, the authors concluded that despite a series of limitations, massage therapy can be safely performed to breast cancer patients during chemotherapy (16).

In 2017, Miladinia M. et al. (17) stated in a randomized controlled trial within 60 patients with acute leukemia, a decreasing of pain, fatique or sleep disruption (measured by using numeric rated scales) following a 4 weeks period of slow stroke back massage lasting 10 minutes, 3 times per week - excepting the situation when they had less than 15,000 platelets $(9,17)$.

Another study including 20 patients with leukemia was randomized by Taylor. They were given 50 minutes of Swedish massage by trained therapists, three times a week, 7 weeks and the author could notice a reducing of stress doubled by an increasing of relaxation, following the therapies. Still, the QoL was not significantly modified $(9,18)$. 


\section{DISCUSSION}

As studies stated that the stress generated by this diagnostic and its related symptomatology affects negatively the immune response, a complementary method to diminish it might be the right choice $(3,5)$.

It is to be mentioned also the benefits of this widely used method in minimizing the negative effects of chemotherapy in breast cancer patients, so improving their QoL (19).

The sleep disorder, the most prevalent symptom in women diagnosed with cancer, is improved as well, following massage therapy sessions (20).

Moreover, a recent research (2014-2017) investigating the symptoms determined by intrathe- cal therapy/aspiration of bone marrow in children with cancer settled as well massage efficacy by decreasing pain and anxiety of those affected $(21,22)$.

\section{CONCLUSIONS}

Finally, it may be concluded that, based on these evidences, massage therapy has proved its utility in reducing subjective symptoms as pain, anxiety, nausea and fatique in oncologic patients.

Furthermore, carefully designed studies taking into account all aspects regarding different kinds of massage therapy are necessary to help the need of each patient.

Conflict of interest: none declared Financial support: none declared

\section{REFERENCES}

1. Caro MMM, Laviano A, Pichard C. Nutritional intervention and quality of life in adult oncology patients. Clinical Nutrition (2007) 26, 289-301.

2. Nayak MG, George A, Kamath A. Quality of life among cancer patients. Indian Journal of Palliative Care. 2017 Oct-Dec; 23(4):445450.

3. Abrahao CA, Bomfim E, Lopes-Junior LC, Pereira-da-Silva G. Complementary Therapies as a Strategy to Reduce Stress and Stimulate Immunity of Women With Breast Cancer. J Evid Based Integr Med 2019; 24:2515690X19834169.

4. Buckner CA, Lafrenie LM, Denommee JA, Caswell JM, Want DA. Complementary and alternative medicine use in patients before and after a cancer diagnosis. Curr Oncol. 2018 Aug; 25(4): 275-281.

5. Falkensteiner M, Mantovan F, Muller I, Them C. The Use of Massage Therapy for Reducing Pain, Anxiety, and Depression in Oncological Palliative Care Patients: A Narrative Review of the Literature. ISRN Nurs. 2011; 2011:929868.

6. Corbin L. Safety and efficacy of massage therapy for patients with cancer. Cancer Control. 2005; 12(3):158-164.

7. Russel CN, Sumler SS et al. Role of massage therapy in cancer care. The Journal of Alternative and Complementary Medicine. 2008:14, 209-214.

8. Field T. Pediatric massage therapy research: A Nararative Review. Complementery and Integrative Movement Therapies for Children. 2019; 6(6):78.

9. Jacobs S, Mowbray C. The Power of Massage in Children with Cancer - How Can We Do Effective Research? Children. 2019 Jan; 6(1):13.
10. Mazlum S, Chaharsoughi NT, Banihashem A, Vashani HB. The effect of massage therapy on chemotherapy-induced nausea and vomiting in pediatric children. Iran $\mathrm{J}$ Nurs Midwifery Res. 2013; 18, 280-284.

11. Rodriguez-Mansilla J, Gonzalez-Sanchez B, Torres-Piles S, Martin JG, JimenezPalomares M, Bellino MN. Effects of the application of therapeutic massage in children with cancer: A systematic review. Rev. Lat. Am. Enferm. 2017; 25, e2903.

12. Graef MD, McLaughlin Crabtree V, Srivastava DK, Li C. Sleep and mood during hospitalization for high-dose chemotherapy and hematopoietic rescue in pediatric medulloblastoma. Psychooncology. $2018 \mathrm{Jul}$ 27(7):1847-1853

13. Jacobs S, Mowbray C, Cates L.M, Baylor A, Gable C, Skora E, Estrada M, Cheng Y, Wang J, Lewin $D$ et al. Pilot study of massage to improve sleep and fatigue in hospitalized adolescents with cancer. Pediatr. Blood Cancer. 2016; 63, 880-886.

14. Williams KE, Berthelsen D, Walker S, Nicholson JM. A Developmental Cascade Model of Behavioral Sleep Problems and Emotional and Attentional Self-Regulation Across Early Childhood. Behav. Sleep Med. 2017; 15:1-21.

15. Kinkead BSP, Larson ER, Carroll D, Sharenko M, Nettles J, Edwards SA, Miller AH, Torres MA, Dunlop BW, Rakofsky JJ et al. Massage therapy decreases cancerrelated fatigue: Results from a randomized early phase trial. Cancer. 2018; 124:546-554.

16. Mao JJ, Wagner EK, Seluzicki MC, Galindez KL, Sheaffer H, Fox RK. Integrating Oncology Massage Into
Chemoinfusion Suites: A Program Evaluation. Journal of Oncology Practice. 2017; 13(3):e207-e216.

17. Miladinia M, Baraz S, Shariati A, Malehi AS. Effects of Slow-Stroke Back Massage on Symptom Cluster in Adult Patients With Acute Leukemia: Supportive Care in Cancer Nursing. Abstr. in Cancer Nurs. 2017; 40(1):31-38.

18. Taylor AG, Snyder AE, Anderson JG, Brown CJ, Densmore JJ, Bourguignon C. Gentle Massage Improves Disease- and Treatment-Related Symptoms in Patients with Acute Myelogenous Leukemia. J. Clin. Trials. 2014;4:pii:1000161.

19. Sturgeon M, Wetta-Hall R, Hart T, Good M, Dakhil S. Effects of Therapeutic Massage on the Quality of Life Among Patients with Breast Cancer During Treatment. The Journal of Alternative and Complementary Medicine, 2009; 15(4) 373-380.

20. Kashani F, Kashani P. The effect of massage therapy on the quality of sleep in breast cancer patients. Iran J Nurs Midwifery Res. 2014; 19(2): 113-118.

21. Rodriquez-Mansilla J, Gonzalez-Sanchez B, Núñez Bellino M, Effects of the application of therapeutic massage in children with cancer: A systematic review. Rev Lat Am Enfermagem, 2017; 25: e2903.

22. Çelebioğlu A, Gürol A, Yildirim ZK, Büyükavci M. Effects of massage therapy on pain and anxiety arising from intrathecal therapy or bone marrow aspiration in children with cancer. Int J Nurs Pract. 2015; 21(6):797-804 